\title{
Analysis of risk factors for cervical lymph node metastasis of papillary thyroid microcarcinoma: a study of 268 patients
}

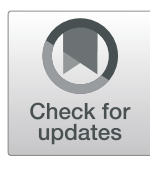

Jian-hua Gu${ }^{1 \dagger}$, Yan-na Zhao ${ }^{2 \dagger}$, Rong-li Xie ${ }^{3}$, Wen-juan Xu', Da-li You ${ }^{4}$, Zhi-feng Zhao ${ }^{5}$, Fei Wang ${ }^{4^{*}}$ (D) and Jian Fei ${ }^{1,5^{*}}$

\begin{abstract}
Background: To investigate the risk factors of cervical lymph node $(L N)$ metastasis in papillary thyroid microcarcinoma (PTMC) patients.

Methods: We retrospectively analyzed the clinicopathologic data of all patients who received standard lobectomy for PTMC at our institution between October 2017 and January 2019. Central LNs were dissected in all patients. Lateral LNs were dissected if metastasis to the lateral LNs was suggested based on pre-op fine-needle aspiration biopsy. The relationship between variables available prior to surgery and cervical LN metastasis was examined using multivariate regression.

Results: Post-op pathologic examination revealed cervical LN metastasis in 79 (29.5\%) patients. Seventy subjects had metastasis only to central LNs, and 4 (1.5\%) patients had metastasis only to lateral LNs. Five patients had metastasis to both central and lateral LNs. In comparison to patients without cervical LN metastasis, those with LN metastasis were significantly younger $(40.63 \pm 13.07$ vs. $44.52 \pm 12.23$ years; $P=0.021)$ and had significantly larger tumor diameter on pathology (6.7 \pm 2.2 vs. $5.9 \pm 2.4 \mathrm{~mm} ; P=0.010)$. Multivariate regression analysis identified the following independent risks for cervical LN metastasis: male sex (OR 2.362, 95\%Cl 1.261 4.425; $P=0.007)$, age (OR 0.977, 95\%Cl 0.956 0.999; $P=0.042)$ and ultrasound tumor diameter at $>5 \mathrm{~mm}(\mathrm{OR} 3.172,95 \% \mathrm{Cl} 1.389 \sim 7.240 ; P=0.006)$.
\end{abstract}

Conclusion: Cervical LN metastasis occurs in a non-insignificant proportion of PTMC patients. Independent risks included male sex, younger age and larger tumor diameter on ultrasound.

Keywords: Papillary thyroid microcarcinoma, Cervical lymph node metastasis, Cervical lymph node dissection

\section{Background}

According to the World Health Organization (WHO) report, the number of new cases of thyroid cancer in China accounted for $15.6 \%$ of that worldwide, and the number of deaths accounted for $13.8 \%$ [1]. Papillary thyroid carcinoma (PTC) is the most common pathological type of thyroid malignancy and accounts for about 85 to $90 \%$ of all cases of thyroid malignancies. PTC with a maximum tumor diameter of $10 \mathrm{~mm}$ or less is defined as papillary thyroid microcarcinoma (PTMC) [2]. Several

\footnotetext{
* Correspondence: chazwf@163.com; feijian@hotmail.com

†jian-hua Gu and Yan-na Zhao contributed equally to this work.

${ }^{4}$ Department of Critical Care Medicine, Jiading District Central Hospital

Affiliated Shanghai University of Medicine \& Health Sciences, Shanghai, China

${ }^{1}$ Department of General Surgery, Shanghai Ruijin Rehabilitation Hospital,

Shanghai, China

Full list of author information is available at the end of the article
}

studies have indicated that PTMC has a low rate of recurrence and metastasis [3] as well as an extremely high 10 -year survival rate [4]. In recent years, improvements in diagnostic methods such as imaging and ultrasoundguided fine needle aspiration biopsy have led to a significant increase in the diagnosis rate of PTMC [5].

The most common site of PTMC metastasis is cervical lymph nodes, especially the central lymph nodes (known as level 6) [6,7]. Surgery remains the main therapeutic modality for PTMC: it is a consensus that patients with cervical LN metastasis be managed by LN dissection; however, the necessity of LN dissection in patients with clinically negative lymph nodes (cN0) has been debated [8]. Active surveillance data from Japan suggested that even those at risk for disease progression such as young age and pregnancy should be actively monitored instead 
of surgery [2]. On the other hand, cervical LN metastasis increases the risk of loco-regional recurrence of PTC [9]. As a result, it is important to identify predictors of cervical LN metastasis.

In the current retrospective analysis, we examined the potential correlation between pre-operative variables with cervical LN metastasis in 268 PTMC patients.

\section{Methods}

The current study (including access to raw data) was approved by the Ethics Committee of Shanghai Ruijin Rehabilitation Hospital (Committee Chairman: Ms. Yuezhen Dai) and performed in accordance with the Declaration of Helsinki and Good Clinical Practice guidelines. Patient consent was not required because of the retrospective nature of the study. Anonymized patient data (in the Chinese language) are available upon request.

\section{Patients}

This retrospective study analyzed the clinical data of pathologically proven PTMC patients who were initially treated at Shanghai Ruijin Rehabilitation Hospital, Shanghai, China, between October 2017 and January 2019. Patients were included if 1 ) they received initial diagnosis and treatment for thyroid nodules; 2) they were diagnosed with PTMC by preoperative fine-needle biopsy and underwent conventional lobectomy of thyroid carcinoma; 3) they had pathologically proven solitary PTMC; 4) the maximum tumor diameter on pathology was $\leq 10 \mathrm{~mm}$.

\section{Patient evaluation}

The following data were retrieved from the hospital electronic record systems: name, sex and age and clinicopathologic and surgical data including 1) time to surgery from initial presentation; 2) surgical procedure received; 3) pathological type, maximum diameter and location (classified as inferior, middle, superior, or isthmus within the thyroid gland) of the tumor; 4) histological results of involved central and/or lateral lymph nodes; 5) concurrent Hashimoto's thyroiditis; 6) routine laboratory results such as blood chemistries, thyroid function, parathyroid hormone and blood calcium before and following operation.

All patients underwent preoperative physical examination, high-quality thyroid ultrasonography (US), and US-guided fine-needle aspiration biopsy of suspected thyroid nodule or lymph nodes. Solitary PTMC was considered if the tumor showed no pathological evidence of multifocality within the thyroid gland. The maximum diameter and location of the primary tumor within the thyroid were determined by pathological examination.

\section{Surgery}

All patients underwent standard lobectomy. Central LN dissection was conducted in all subjects. In patients suspected of metastasis to lateral LNs based ultrasound examination prior to surgery, lateral LNs were also

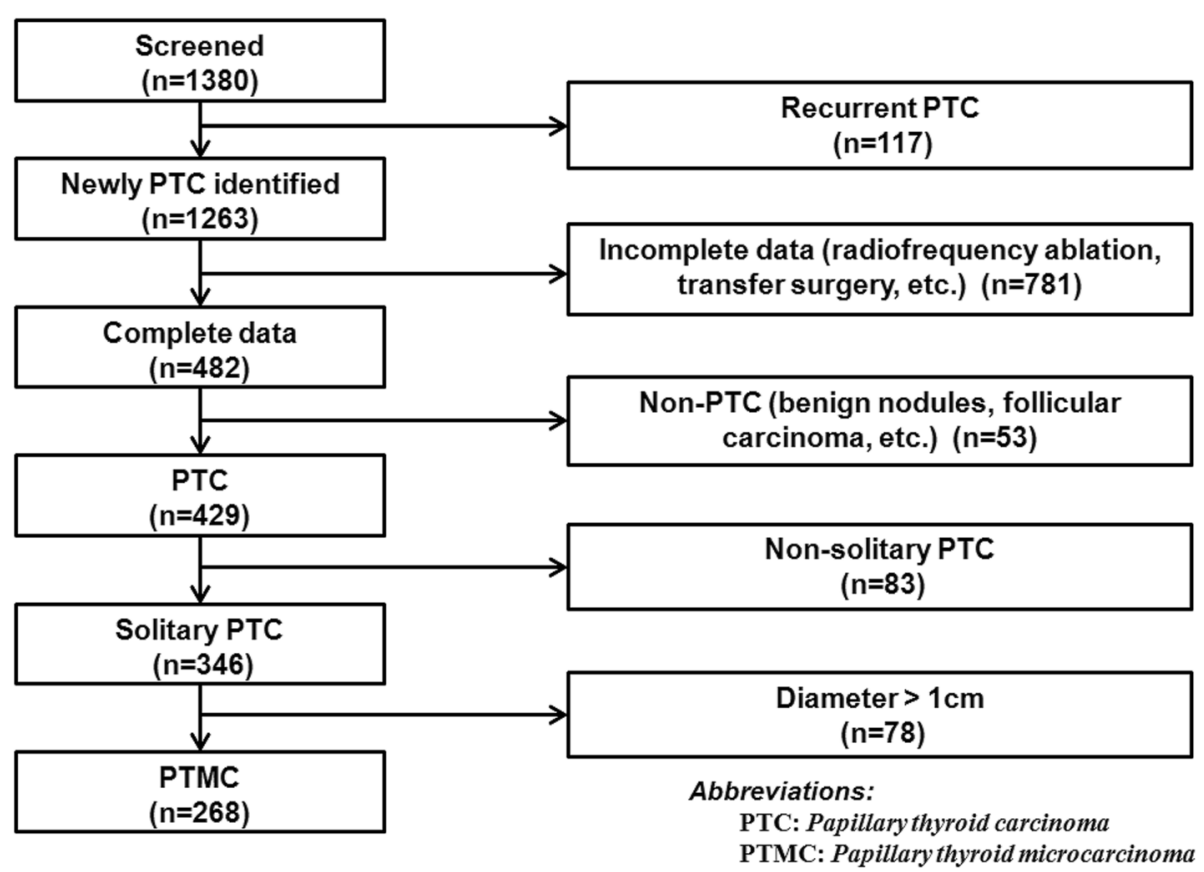

Fig. 1 The study flowchart 
dissected. The excised tissue was then sent for pathological examination. Patients received routine rehydration as well as symptomatic treatment postoperatively and were closely observed for incision hemorrhage, hoarseness, or numbness.

\section{Statistical analysis}

The data was analyzed with SPSS 20.0 software (SPSS Inc., Chicago, IL, USA). Student's $t$-test and $x^{2}$ test were used to examine potential differences between subjects with vs. without cervical LN metastasis. Multivariate logistic regression was used to evaluate the correlation between pre-operative variables and cervical LN metastasis. $P<0.05$ was considered statistically significant.

\section{Results}

\section{Patient demographic and baseline characteristics}

The study flowchart is shown in Fig. 1. A total of 429 patients with a diagnosis of primary PTC with complete data were screened. Eighty-three patients with nonsolitary lesion were excluded and 78 patients were excluded because the maximum tumor diameter on pathology was $>10 \mathrm{~mm}$. The final analysis included 268 patients (208 women; mean age $43.3 \pm 12.6$ years, range 15-72). Demographic and baseline variables are shown in Table 1.

\section{Lymph node metastasis}

Seventy-nine (29.5\%) patients had cervical LN metastasis: 70 subjects had metastasis only to central LNs, and 4 (1.5\%) patients had metastasis only to lateral LNs. Five patients had metastasis to both central and lateral LNs. Compared to patients without LN metastasis, those with cervical LN metastasis were significantly younger $(40.63 \pm 13.07$ vs $44.52 \pm 12.23$ years; $P=0.021)$ and had significantly larger tumor diameter on pathology (6.7 \pm 2.2 vs. $5.9 \pm 2.4 \mathrm{~mm} ; P=0.010$ ) (Table 2). The two groups were comparable in other demographic and baseline variables.

\section{Risks of cervical LN metastasis}

A univariate analysis showed that cervical LN metastasis is associated with the male sex $(P=0.008)$, younger age $(P=0.021)$ and larger tumor diameter on ultrasound $(P=0.010)$. The multivariate analysis confirmed the following risks: male sex (OR 2.362, 95\%CI 1.261 4.425; $P=0.007$ ), younger age (OR $0.977,95 \%$ CI $0.956 \sim 0.999$; $P=0.042)$ and ultrasound tumor diameter at $>5 \mathrm{~mm}$ (OR 3.172, 95\%CI 1.389 7.240; $P=0.006$ ) (Table 3).
Table 1 Patient demographic and baseline characteristics

\begin{tabular}{|c|c|}
\hline Variables & All $(n=268)$ \\
\hline Female sex, $\mathrm{n}(\%)$ & 208(77.6) \\
\hline \multicolumn{2}{|l|}{ Age, years } \\
\hline Mean \pm SD & $43.3 \pm 12.6$ \\
\hline Range & 15,72 \\
\hline \multicolumn{2}{|c|}{ Maximum diameter on pathology, mm } \\
\hline Mean \pm SD & $6.1 \pm 2.4$ \\
\hline Range & 1,10 \\
\hline$>5, \mathrm{n}(\%)$ & $148(55.2)$ \\
\hline \multicolumn{2}{|c|}{ Maximum diameter on ultrasound, mm } \\
\hline Mean \pm SD & $9.8 \pm 6.8$ \\
\hline Range & 2,49 \\
\hline$\leq 5$ & $53(19.8)$ \\
\hline$>5$ & $215(80.2)$ \\
\hline \multicolumn{2}{|l|}{ Location, n(\%) } \\
\hline Superior & $69(25.7)$ \\
\hline Middle & 99 (36.9) \\
\hline Inferior & $77(28.7)$ \\
\hline Isthmus & $15(5.6)$ \\
\hline Missing & $8(3.0)$ \\
\hline \multicolumn{2}{|l|}{ Hashimoto's thyroiditis } \\
\hline Yes & $79(29.5)$ \\
\hline \multicolumn{2}{|l|}{ Capsular invasion, $\mathrm{n}(\%)$} \\
\hline Yes & $52(19.4)$ \\
\hline \multicolumn{2}{|l|}{ Extrathyroidal extension, n(\%) } \\
\hline Yes & $49(18.3)$ \\
\hline Cervical LN metastasis, $\mathrm{n}(\%)$ & $79(29.5)$ \\
\hline Only central & $70(26.1)$ \\
\hline Only lateral & $4(1.5)$ \\
\hline Both central and lateral & $5(1.9)$ \\
\hline
\end{tabular}

\section{Discussion}

In the current study, approximately $30 \%$ PTMC patients had cervical LN metastasis. Independent risk factors included the male sex, younger age and tumor size on ultrasound at $>5 \mathrm{~mm}$. Given the fact that cervical $\mathrm{LN}$ metastasis increases the risk of loco-regional recurrence of PTC [9], our findings suggest that this noninsignificant proportion of at risk PTMC patients should be actively monitored. Based on these findings, we believe that LN dissection is necessary in young men with PTMC with tumor diameter at $>5 \mathrm{~mm}$. Skip metastasis was identified in 4 out of the 268 cases. We therefore did not attempt an analysis to examine the risk of skip metastasis.

In recent years, there has been a noticeable increase in the incidence of thyroid malignancies in China and globally, in which PTMC accounts for a large proportion of 
Table 2 Demographic and baseline characteristics in subjects with vs. without cervical LN metastasis

\begin{tabular}{|c|c|c|c|c|}
\hline Variables & Yes & No & & $P$ \\
\hline N. & 79 & 189 & & \\
\hline Female sex, $\mathrm{n}(\%)$ & $53(67.1)$ & $155(82.0)$ & & 0.008 \\
\hline \multicolumn{5}{|l|}{ Age, years } \\
\hline Mean \pm SD & $40.63 \pm 13.07$ & $44.52 \pm 12.23$ & & 0.021 \\
\hline Range & 15,67 & 22,72 & & \\
\hline \multicolumn{5}{|l|}{$\begin{array}{l}\text { Maximum diameter } \\
\text { on pathology, mm }\end{array}$} \\
\hline Mean \pm SD & $6.7 \pm 2.2$ & $5.9 \pm 2.4$ & & 0.010 \\
\hline Range & 2,10 & 1,10 & & \\
\hline$\leq 5$ & $29(36.7)$ & $91(48.1)$ & & 0.086 \\
\hline$>5$ & $50(63.3)$ & $98(51.9)$ & & \\
\hline \multicolumn{5}{|l|}{$\begin{array}{l}\text { Maximum diameter } \\
\text { on ultrasound, } \mathrm{mm}\end{array}$} \\
\hline $\begin{array}{l}\text { Median } \\
\text { (interquartile range) }\end{array}$ & $9.1(6.9 \sim 11.2)$ & $7.8(5.4 \sim 10.6)$ & & 0.015 \\
\hline Range & $3,45.8$ & 2,49 & & \\
\hline$\leq 5$ & $8(10.1)$ & $45(23.8)$ & & 0.010 \\
\hline$>5$ & $71(89.9)$ & $144(76.2)$ & & \\
\hline Location, n(\%) & & & & 0.957 \\
\hline Superior & $21(27.6)$ & $48(26.1)$ & & \\
\hline Middle & $29(38.2)$ & $70(38.0)$ & & \\
\hline Inferior & $21(27.6)$ & $56(30.4)$ & & \\
\hline Isthmus & $5(6.6)$ & $10(5.4)$ & & \\
\hline Missing & $8(3.0)$ & & & \\
\hline Hashimoto's thyroiditis & & & 0.248 & 0.618 \\
\hline Yes & $19(20.3)$ & $51(27.0)$ & & \\
\hline Capsular invasion & & & 0.321 & 0.571 \\
\hline Yes & $17(21.5)$ & $35(18.5)$ & & \\
\hline Extrathyroidal extension & & & 0.785 & 0.376 \\
\hline Yes & $17(21.5)$ & $32(16.9)$ & & \\
\hline
\end{tabular}

all thyroid cancer cases [10]. The rate of cervical LN metastasis in PTMC patients has been reportedly from 12 to $64 \%$ [7]; the rate of cervical LN metastasis in our study (29.5\%) falls within this range. Cervical LN metastasis is associated with tumor stage, invasiveness and recurrence rate, and serves as one of the essential

Table 3 Multivariate analysis of risk factors for cervical LN metastasis

\begin{tabular}{llll}
\hline & OR & $95 \% \mathrm{Cl}$ & $P$ \\
\hline Male sex & 2.362 & $1.261 \sim 4.425$ & 0.007 \\
Age & 0.977 & $0.956 \sim 0.999$ & 0.042 \\
$\begin{array}{l}\text { Maximum diameter on } \\
\text { ultrasound, }>5 \mathrm{~mm}\end{array}$ & 3.172 & $1.389 \sim 7.240$ & 0.006 \\
\hline
\end{tabular}

The analysis included a total of 268 subjects: 79 with cervical LN metastasis prognostic predictors of PTMC [11, 12]. Although thyroid malignancies are now diagnosed at an early stage owing to recent advances in imaging technologies, image reading can be influenced by multiple factors such as tumor characteristics and physicians' skills.

In current consensus, LN dissection should be performed in PTMC patients with pathologically confirmed cervical LN metastasis. Whether cervical LNs should be routinely dissected in cNO PTMC patients remains controversial. A previous study suggested that LN dissection had no significant effect on the recurrence and metastatic rate of PTMC [13].

Based on previous literature, independent risk factors of cervical LN metastasis in PTMC patients include age over 45 years [14], male sex [14, 15], larger tumor diameter [16] and capsule invasion $[6,7,16]$. Other clinicopathologic variables associated with cervical LN metastasis may include lesion location [17], multifocality (the number of lesions no less than 2) [18-21], and concurrent Hashimoto's thyroiditis [15, 22]. Our study focused on solitary PTMC and found that tumor diameter on ultrasound at $>5 \mathrm{~mm}$ is an independent risk of cervical $\mathrm{LN}$ metastasis in PTMC $(\mathrm{OR}=3.172, P=0.006)$. The current study also revealed an association between cervical LN metastasis with younger age $(\mathrm{OR}=0.977$, $P=0.042)$ and the male sex $(\mathrm{OR}=2.362, P=0.007)$. We failed to show an association between cervical LN metastasis with tumor location, capsule invasion or Hashimoto's thyroiditis, possibly due to insufficient sample size.

The availability of gene sequencing data may allow molecular stratification of cancer patients. Lai et al. showed in a meta-analysis that BRAF ${ }^{\mathrm{V} 600 \mathrm{E}}$ mutation was associated with extra-thyroid infiltration, lymph node and distant metastasis, and advanced TNM staging. Therefore, determination of BRAF mutation status preoperatively may allow preoperative evaluation of capsule invasion and cervical LN metastasis. However, more studies are required to validate of molecular markers such as BRAF.

With the development of medical technology, PTMC patients now have more options for treatment. In addition to the more aesthetically pleasing surgical methods such as thyroidectomy with laparoscopy or robot-assisted surgery, radiofrequency ablation therapy has also garnered the interest of clinicians. Based on the findings from the current study, we believe that ablation may be suitable for selected patients (older age, women, tumor diameter at $\leq 5 \mathrm{~mm}$ ) with low risk of cervical LN metastasis.

\section{Conclusion}

Cervical LN metastasis is not a rare occurrence in PTMC patients. Independent risks for metastasis include the male sex, younger age and tumor diameter on ultrasound at $>5 \mathrm{~mm}$. 


\section{Abbreviations}

BRAF: V-raf murine sarcoma viral oncogene homolog B1; LN: Lymph node; PTC: Papillary thyroid carcinoma; PTMC: Papillary thyroid microcarcinoma; US: Ultrasonography

\section{Acknowledgements}

Not applicable.

\section{Authors' contributions}

GJH and ZYN: carried out the studies, participated in collecting data, and drafted the manuscript. XWJ, ZZF and YDL: participated in collecting data and helped to draft the manuscript. XRL: performed the statistical analysis. WF and FJ: design, review and editing the manuscript. All authors read and approved the final manuscript.

\section{Funding}

This study was supported in part by the Public Health Bureau of Shanghai Municipal Huangpu District (\# HKW201615). The funding sources had no role in the design of the study; in the collection, analysis, and interpretation of data; or in the writing of the manuscript.

\section{Availability of data and materials}

The data that support the findings of this study are available from the corresponding author upon reasonable request.

\section{Ethics approval and consent to participate}

The study protocol was approved by the Ethics Committee of Shanghai Ruijin Rehabilitation Hospital and the study was performed in accordance with the Declaration of Helsinki and Good Clinical Practice guidelines. Patient consent was not required because of the retrospective nature of the study. Patient data were anonymized.

\section{Consent for publication}

Not applicable.

\section{Competing interests}

The authors declare that they have no competing interests.

\section{Author details}

'Department of General Surgery, Shanghai Ruijin Rehabilitation Hospital, Shanghai, China. ${ }^{2}$ Department of Ultrasound, Shanghai Ruijin Rehabilitation Hospital, Shanghai, China. ${ }^{3}$ Department of Surgery, Luwan Branch, Ruijin Hospital affiliated to Shanghai Jiao Tong University School of Medicine, Shanghai, China. ${ }^{4}$ Department of Critical Care Medicine, Jiading District Central Hospital Affiliated Shanghai University of Medicine \& Health Sciences, Shanghai, China. ${ }^{5}$ Department of General Surgery, Ruijin Hospital, Shanghai Jiao Tong University School of Medicine, Shanghai, China.

Received: 22 May 2019 Accepted: 28 October 2019

Published online: 15 November 2019

\section{References}

1. McGuire S. World Cancer report 2014. Geneva, Switzerland: World Health Organization, International Agency for Research on Cancer, WHO press, 2015. Adv Nutr. 2016;7(2):418-9.

2. Ito $Y$, Miyauchi $A$, Oda H. Low-risk papillary microcarcinoma of the thyroid: a review of active surveillance trials. Eur J Surg Oncol. 2018:44(3):307-15.

3. Roti E. Degli Uberti EC, Bondanelli M, Braverman LE. Thyroid papillary microcarcinoma: a descriptive and meta-analysis study. Eur J Endocrinol. 2008;159(6):659-73.

4. Wang TS, Goffredo P, Sosa JA, Roman SA. Papillary thyroid microcarcinoma: an over-treated malignancy? World J Surg. 2014;38(9):2297-303.

5. Kim BY, Jung CH, Kim JW, Lee SW, Kim CH, Kang SK, et al. Impact of clinicopathologic factors on subclinical central lymph node metastasis in papillary thyroid microcarcinoma. Yonsei Med J. 2012;53(5):924-30.

6. Cho SY, Lee TH, Ku YH, Kim HI, Lee GH, Kim MJ. Central lymph node metastasis in papillary thyroid microcarcinoma can be stratified according to the number, the size of metastatic foci, and the presence of desmoplasia. Surgery. 2015;157(1):111-8
7. Zhao Q, Ming J, Liu C, Shi L, Xu X, Nie X, et al. Multifocality and total tumor diameter predict central neck lymph node metastases in papillary thyroid microcarcinoma. Ann Surg Oncol. 2013;20(3):746-52.

8. Leboulleux S, Tuttle RM, Pacini F, Schlumberger M. Papillary thyroid microcarcinoma: time to shift from surgery to active surveillance? Lancet Diabetes Endocrinol. 2016;4(11):933-42.

9. Hughes CJ, Shaha AR, Shah JP, Loree TR. Impact of lymph node metastasis in differentiated carcinoma of the thyroid: a matched-pair analysis. Head Neck. 1996:18(2):127-32

10. Abboud B, Daher R, Sleilaty G, Abadjian G, Ghorra C. Are papillary microcarcinomas of the thyroid gland revealed by cervical adenopathy more aggressive? Am Surg. 2010;76(3):306-11.

11. Pellegriti G, Scollo C, Lumera G, Regalbuto C, Vigneri R, Belfiore A. Clinical behavior and outcome of papillary thyroid cancers smaller than $1.5 \mathrm{~cm}$ in diameter: study of 299 cases. J Clin Endocrinol Metab. 2004:89(8):3713-20.

12. Lombardi CP, Bellantone R, De Crea C, Paladino NC, Fadda G, Salvatori M, et al. Papillary thyroid microcarcinoma: extrathyroidal extension, lymph node metastases, and risk factors for recurrence in a high prevalence of goiter area. World J Surg. 2010;34(6):1214-21.

13. Wada N, Duh QY, Sugino K, Iwasaki H, Kameyama K, Mimura T, et al. Lymph node metastasis from 259 papillary thyroid microcarcinomas: frequency, pattern of occurrence and recurrence, and optimal strategy for neck dissection. Ann Surg. 2003;237(3):399-407.

14. Li F, Wu Y, Chen L, Hu L, Liu X. Evaluation of clinical risk factors for predicting insidious right central and posterior right recurrent laryngeal nerve lymph node metastasis in papillary thyroid microcarcinoma patients (cN0): experience of a single center. Ann Transl Med. 2019;7(1):8.

15. Mao LN, Wang P, Li ZY, Wang Y, Song ZY. Risk factor analysis for central nodal metastasis in papillary thyroid carcinoma. Oncol Lett. 2015;9(1):103-7.

16. Li M, Zhu XY, Lv J, Lu K, Shen MP, Xu ZL, et al. Risk factors for predicting central lymph node metastasis in papillary thyroid microcarcinoma (cNO): a study of 273 resections. Eur Rev Med Pharmacol Sci. 2017;21(17):3801-7.

17. Zhang L, Wei WJ, Ji QH, Zhu YX, Wang ZY, Wang Y, et al. Risk factors for neck nodal metastasis in papillary thyroid microcarcinoma: a study of 1066 patients. J Clin Endocrinol Metab. 2012;97(4):1250-7.

18. Cheng F, Chen Y, Zhu L, Zhou B, Xu Y, Chen Y, et al. Risk factors for cervical lymph node metastasis of papillary thyroid microcarcinoma: a single-center retrospective study. Int J Endocrinol. 2019;2019:8579828.

19. Zheng KS, Zeng Y, Chen C, Wu YZ, Chen B, Ying WB, et al. Risk factors of cervical lymph node metastasis in papillary thyroid microcarcinoma: An analysis based on data from the Surveillance, Epidemiology and End Results Database. Zhongguo Yi Xue Ke Xue Yuan Xue Bao. 2018;40(6):736-43 [Article in Chinese].

20. Xiang T, Yan W, Zhou L. Retrospective analysis of prognostic factors in patients of papillary thyroid microcarcinoma. Oncotarget. 2018;9(85):35553-8.

21. Luo Y, Zhao Y, Chen K, Shen J, Shi J, Lu S, et al. Clinical analysis of cervical lymph node metastasis risk factors in patients with papillary thyroid microcarcinoma. J Endocrinol Investig. 2019:42(2):227-36.

22. Xiang D, Xie L, Xu Y, Li Z, Hong Y, Wang P. Papillary thyroid microcarcinomas located at the middle part of the middle third of the thyroid gland correlates with the presence of neck metastasis. Surgery. 2015;157(3):526-33.

\section{Publisher's Note}

Springer Nature remains neutral with regard to jurisdictional claims in published maps and institutional affiliations.

Ready to submit your research? Choose BMC and benefit from:

- fast, convenient online submission

- thorough peer review by experienced researchers in your field

- rapid publication on acceptance

- support for research data, including large and complex data types

- gold Open Access which fosters wider collaboration and increased citations

- maximum visibility for your research: over $100 \mathrm{M}$ website views per year

At $\mathrm{BMC}$, research is always in progress.

Learn more biomedcentral.com/submissions 